\title{
Hydrothermal Synthesis and Characterization of Single-Crystalline $\alpha-\mathrm{Fe}_{2} \mathrm{O}_{3}$ Nanocubes
}

\author{
Wenqing Qin, ${ }^{1,2}$ Congren Yang, ${ }^{1,2}$ Ran Yi, ${ }^{1,2}$ and Guanhua Gao ${ }^{1,2}$ \\ ${ }^{1}$ School of Minerals Processing and Bioengineering, Central South University, Changsha, Hunan 410083, China \\ ${ }^{2}$ Key Laboratory of Biometallurgy of Ministry of Education, Central South University, Changsha, Hunan 410083, China
}

Correspondence should be addressed to Wenqing Qin, qinwenqing369@126.com

Received 11 April 2010; Accepted 15 June 2010

Academic Editor: Quanqin Dai

Copyright ( 2011 Wenqing Qin et al. This is an open access article distributed under the Creative Commons Attribution License, which permits unrestricted use, distribution, and reproduction in any medium, provided the original work is properly cited.

\begin{abstract}
Single-crystalline $\alpha-\mathrm{Fe}_{2} \mathrm{O}_{3}$ nanocubes were successfully obtained in large quantities through a facile one-step hydrothermal synthetic route under mild conditions. In this synthetic system, aqueous iron (III) nitrate $\left(\mathrm{Fe}\left(\mathrm{NO}_{3}\right)_{3} \cdot 9 \mathrm{H}_{2} \mathrm{O}\right)$ served as iron source and triethylamine served as precipitant and alkaline agent. By prolonging reaction time from $1 \mathrm{~h}$ to $24 \mathrm{~h}$, the evolution process of $\alpha-\mathrm{Fe}_{2} \mathrm{O}_{3}$, from nanorhombohedra to nanohexahedron, and finally nanocube, was observed. The products were characterized by Powder X-ray Diffraction (XRD), Scanning Electron Microscopy (SEM), Transmission Electron Microscopy (TEM), Highresolution Transmission Electron Microscopy (HRTEM), Selected-Area Electron Diffraction (SAED), and Fourier Transform Infrared Spectrometry (FTIR). The possible formation mechanism was discussed on basis of the experimental results.
\end{abstract}

\section{Introduction}

Iron oxides are conventional semiconductor materials, mainly in forms of $\alpha$ - and $\gamma-\mathrm{Fe}_{2} \mathrm{O}_{3}$. The unit cell of $\alpha-\mathrm{Fe}_{2} \mathrm{O}_{3}$ (hematite) is hexagonal, containing only octahedral coordinated $\mathrm{Fe}^{3+}$ atoms (corundum structure), while $\gamma-\mathrm{Fe}_{2} \mathrm{O}_{3}$ (magnetite) particles have cubic unit cells with both octahedral and tetrahedral coordinated $\mathrm{Fe}^{3+}$ sites (defect spinel structure) [1]. They are both technologically important because of their special magnetic and electrical properties, and potential applications in sorbents [2], ion exchangers [3], information storage [4], and magnetic refrigeration [5]. Controlling the morphologies of these materials during synthetic process is of great importance because of their shape-dependent properties. Various synthetic methods are continually being improved. To date, a variety of novel shapes of iron oxides nanocrystals have been successfully synthesized via various approaches. Magnetite nanorods with high aspect ratio have been synthesized by one-step wet chemistry process that a surfactant, polyethylene glycol, served as the template, and a ferrous ammonia sulphate served as iron source [6]. Uniform $\alpha-\mathrm{Fe}_{2} \mathrm{O}_{3}$ particles within the nanometer range $(100-300 \mathrm{~nm})$ have been obtained by precipitation of iron (III) perchlorate in the presence of urea.
Different morphology, from spheres to ellipsoidal particles with axial ratio up to 10 , was obtained by adding to the initial solution increasing amounts of phosphate anions up to $7 \mathrm{mM}$ [7]. Plate-shaped $\gamma-\mathrm{Fe}_{2} \mathrm{O}_{3}$ nanocrystals have been successfully prepared in a water system by a simple reduction-oxidation method at room temperature and under ambient pressure. The reactions contain two steps: first, $\mathrm{Fe}(\mathrm{II})$ is reduced into $\mathrm{Fe}$ atoms by $\gamma$-ray irradiation in nitrogen atmosphere; then, $\mathrm{Fe}$ atoms are oxidized into $\gamma$ $\mathrm{Fe}_{2} \mathrm{O}_{3}$ in air [8]. Continuous iron oxide gel fibers were prepared by the sol-gel method using ferric alkoxide and acetic acid as starting materials and alcohol as solvent, and continuous hollow $\alpha-\mathrm{Fe}_{2} \mathrm{O}_{3}$ fibers produced after the gel fibers were heat treated at 400 degrees $\mathrm{C}$ for 1 hour [9]. Vertically aligned iron oxide nanobelt and nanowire arrays have been synthesized on a large-area surface by direct thermal oxidation of iron substrates under the flow of $\mathrm{O}_{2}$. It was found that nanobelts (width, tens of nanometers; thickness, a few nanometers) were produced in the low-temperature region (similar to $700^{\circ} \mathrm{C}$ ) whereas cylindrical nanowires which are tens of nanometers thick are formed at relatively higher temperatures (similar to $800^{\circ} \mathrm{C}$ ) [10]. Sphere-like maghemite $\left(\gamma-\mathrm{Fe}_{2} \mathrm{O}_{3}\right)$ nanocrystals are formed by utilizing a solution-based one-step thermolysis method; modulating 
the growth parameters, such as the type and amount of capping ligands as well as the growth time, is shown to have a significant effect on the overall shape and size of the obtained nanocrystals and on the ripening process itself [11]. Hou et al. report a facile organic-phase synthesis of monodisperse $\mathrm{FeO}$ nanoparticles through high-temperature reductive decomposition of iron (III) acetylacetonate ([Fe$\left.(\mathrm{acac})_{3}\right]$ ) with oleic acid $(\mathrm{OA})$ and oleylamine $(\mathrm{OAm})$ both as surfactants and solvents; the sizes of the particles are tuned from 14 to $100 \mathrm{~nm}$ by controlling the heating conditions and the shapes of the particles are controlled to be either spherical or truncated octahedral depending on the volume ratio of $\mathrm{OA}$ and $\mathrm{OAm}$ used in the reaction. Thermal annealing under an argon atmosphere converted these $\mathrm{FeO}$ nanoparticles into composite $\mathrm{Fe}-\mathrm{Fe}_{3} \mathrm{O}_{4}$ nanoparticles, while controlled oxidation of the $\mathrm{FeO}$ nanoparticles resulted in the formation of $\mathrm{Fe}_{3} \mathrm{O}_{4}, \gamma-\mathrm{Fe}_{2} \mathrm{O}_{3}$, or $\alpha-\mathrm{Fe}_{2} \mathrm{O}_{3}$ nanoparticles [12]. The highly crystalline and monodisperse $\gamma$ - $\mathrm{Fe}_{2} \mathrm{O}_{3}$ nanocrystallites are fabricated from the controlled oxidation of uniform iron nanoparticles which are generated from the thermal decomposition of iron complex. Particle size can be varied from 4 to $16 \mathrm{~nm}$ by controlling the experimental parameters [13]. Nevertheless, the production of $\mathrm{Fe}_{2} \mathrm{O}_{3}$ nanocubes has not been realized ever. Nanocubes exposed a specific surface, which provided an ideal model for the study of surface related properties [14, 15].

In this paper, we demonstrated that single-crystalline $\alpha-\mathrm{Fe}_{2} \mathrm{O}_{3}$ nanocubes could be successfully synthesized via a facile hydrothermal synthetic method under mild conditions. The morphologies of $\alpha-\mathrm{Fe}_{2} \mathrm{O}_{3}$ samples could be easily controlled via simply varying the reaction time, and the probable formation mechanism was proposed to explain their growth processes. Moreover, this synthetic approach provided a simple and economical route to synthesize nanocrystals, some of which have a variety of potential applications.

\section{Experimental Procedures}

The aqueous iron (III) nitrate $\left(\mathrm{Fe}\left(\mathrm{NO}_{3}\right)_{3} \cdot 9 \mathrm{H}_{2} \mathrm{O}\right)$ was purchased from Sinopharm Chemical Reagent Co., Ltd. The triethylamine was purchased from Beijing Chemical Factory, China. Both $\mathrm{Fe}\left(\mathrm{NO}_{3}\right)_{3} \cdot 9 \mathrm{H}_{2} \mathrm{O}$ and triethylamine were of analytical grade and no further purification was conducted. Deionized water was used throughout the experiment.

2.1. Synthesis. In a typical procedure, $0.404 \mathrm{~g} \mathrm{Fe}\left(\mathrm{NO}_{3}\right)_{3}$ $.9 \mathrm{H}_{2} \mathrm{O}$ and $3 \mathrm{~mL}$ triethylamine were dissolved in deionized water $(10 \mathrm{~mL})$ to form a homogeneous solution and then the solution was stirred vigorously for 5 minutes. After that, the solution was sealed in a $50 \mathrm{~mL}$ teflon-lined autoclave filled with deionized water till up to $80 \%$ of the total volume, and the container was maintained at $160^{\circ} \mathrm{C}$ for $1-24$ hours without shaking or stirring. The resulting products were filtered and then washed successively with deionized water and anhydrous ethanol for several times, and finally, the product was dried for $5 \mathrm{~h}$ under vacuum at a temperature of $50^{\circ} \mathrm{C}$.

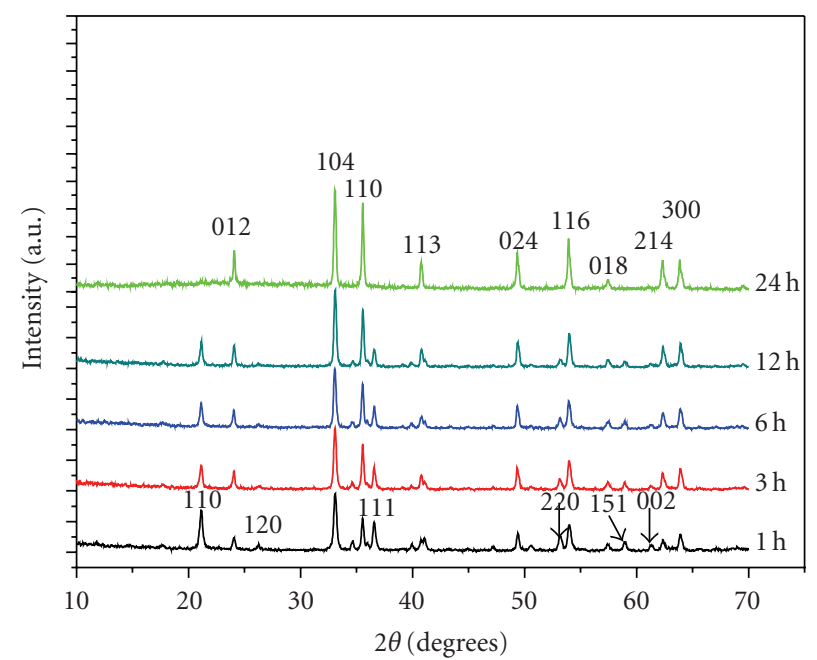

FIGURE 1: X-ray powder diffraction pattern of various as-prepared sample.

2.2. Characterization. The obtained samples were characterized by powder X-ray diffraction (XRD) with a $\mathrm{D} / \max 2550$ $\mathrm{VB}+$, and $\mathrm{Cu} \mathrm{K} \alpha(\lambda=1.54178 \AA)$ was used as the radiation source, while the operation voltage and current were kept at $40 \mathrm{kV}$ and $40 \mathrm{~mA}$, respectively. Particle size and morphology of the as-synthesized products were observed using field emission scanning electron microscopy (FESEM) with Philips XL30 S-FEG at an accelerating voltage of $20 \mathrm{kV}$ and transmission electron microscopy (TEM) with JEM-200CX at an accelerating voltage of $160 \mathrm{kV}$ and high-resolution transmission electron microscopy (HRTEM) with JEOL JEM-2010F at an accelerating voltage of $200 \mathrm{kV}$. Meanwhile, selected area electron diffraction (SAED) was performed to identify the crystallinity. The Fourier transform infrared (FTIR) spectra was recorded on a Nicolet Impact 410 infrared spectrophotometer, and, as for sample preparation, the synthesized powder was added into $\mathrm{KBr}$ to press a $\mathrm{KBr}$ pellet for FTIR analysis.

\section{Results and Discussion}

3.1. Crystal Structure. XRD pattern of the sample obtained at $160^{\circ} \mathrm{C}$ for 24 hours was shown in Figure 1. It could be concluded that all the diffraction peaks could be readily indexed as the pure rhombohedral $\alpha-\mathrm{Fe}_{2} \mathrm{O}_{3}(a=5.038 \AA$, $c=13.772 \AA$ ) (JCPDS file Card, no. 33-0664). The XRD diffraction patterns peaks of $\alpha-\mathrm{Fe}_{2} \mathrm{O}_{3}$ became narrower with prolonging the reaction time, and the narrower peaks suggested that the $\alpha-\mathrm{Fe}_{2} \mathrm{O}_{3}$ samples were higher crystalline, and it testified that iron oxide nanocrystallines could be synthesized through this method. No other peaks were observed, indicating high purity of the as-prepared samples.

The characteristic peaks of orthorhombic $\alpha$ - FeOOH $(a=$ $4.6048 \AA, b=9.9595 \AA, c=3.023 \AA$ ) (JCPDS file Card, no. 81-0464) were observed in Figure 1 when the reaction time was 1 hour, 3 hours, 6 hours, and 12 hours, but the characteristic peaks of $\alpha$-FeOOH decreased with prolonging 


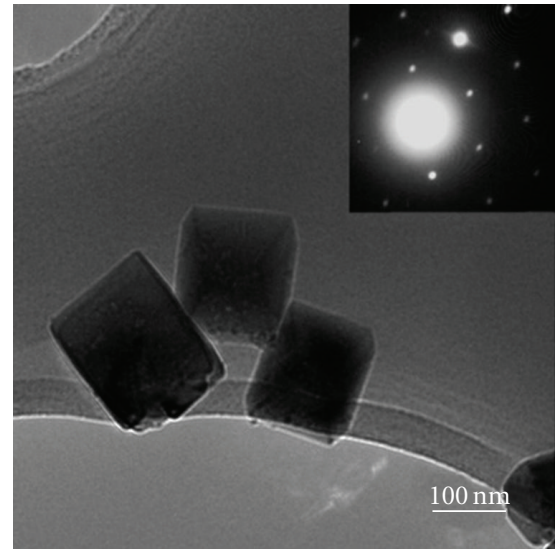

(a)

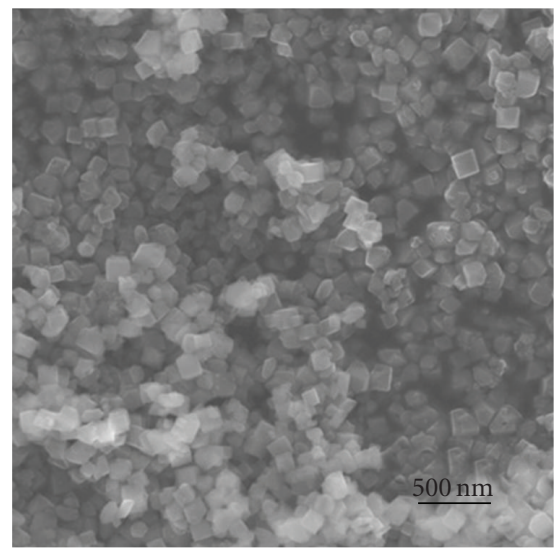

(c)

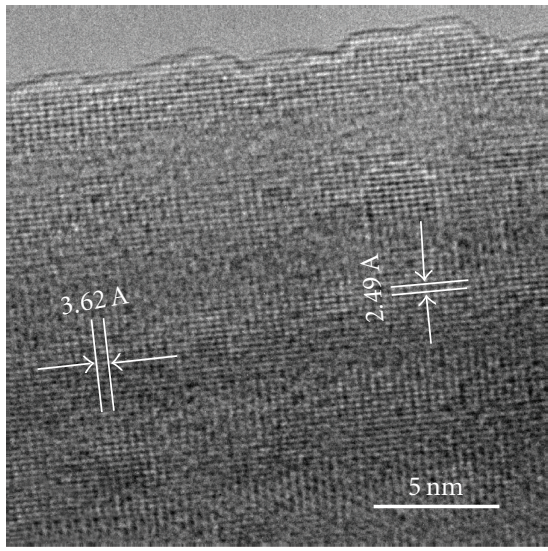

(b)

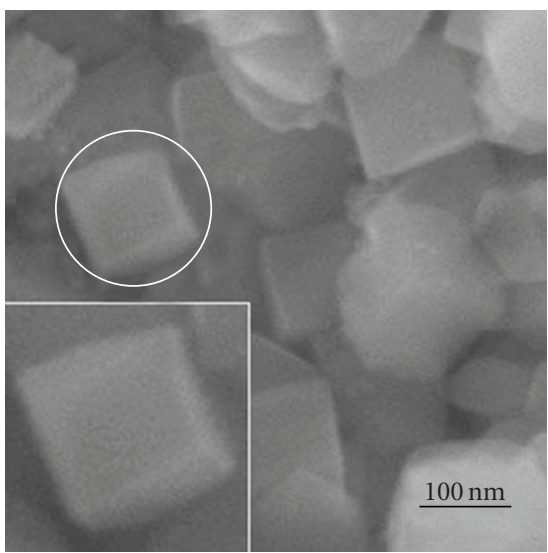

(d)

FIgure 2: (a) TEM image of $\mathrm{Fe}_{2} \mathrm{O}_{3}$ nanocubes prepared at $160^{\circ} \mathrm{C}$ for 24 hours with $3 \mathrm{~mL}$ triethylamine, and the Inset is the SAED image. (b) HRTEM image of the $\mathrm{Fe}_{2} \mathrm{O}_{3}$ nanocubes. (c), (d) SEM images of the $\mathrm{Fe}_{2} \mathrm{O}_{3}$ nanocubes. The Inset in (d) is the high magnification image taken from the highlighted section marked by the circle, which indicates that these particles are nanocubes.

the reaction time, and there were only the characteristic peaks of $\alpha-\mathrm{Fe}_{2} \mathrm{O}_{3}$ when the reaction time was 24 hours. The narrow sharp peaks suggested that the $\alpha-\mathrm{Fe}_{2} \mathrm{O}_{3}$ samples were highly crystalline.

3.2. Morphology. TEM data and analyses of the iron oxide particles prepared at $160^{\circ} \mathrm{C}$ for 24 hours using $3 \mathrm{~mL}$ triethylamine were illustrated in Figure 2(a). These cubes had a regular cubic structure and a uniform width of about 100 to $200 \mathrm{~nm}$. The surfaces of the cubes were equal and the boundaries of them are evident. The SAED pattern in Figure 2(a), which was parallel to uprightness axis of cube surface, indicates that the cubes were single crystallines. The fringe spacing measured $3.62 \AA$ and $2.49 \AA$ (Figure 2(b)), which concurred well with the interplanar spacing of (012) and (110).

Figure 2(c) was a typical SEM image of the $\mathrm{Fe}_{2} \mathrm{O}_{3}$ nanocubes obtained at $160^{\circ} \mathrm{C}$ for 24 hours using $3 \mathrm{~mL}$ triethylamine and Figure $2(\mathrm{~d})$ is the magnified image of Figure 2(c). Both images showed that the regular $\mathrm{Fe}_{2} \mathrm{O}_{3}$ nanocubes could be prepared by this approach. The nanocubes were 100 to $200 \mathrm{~nm}$ in width and the nanocube morphology was more evident in Figure 2(d). The inset in Figure 2(d) was the high-magnification image of a typical particle in the highlighted section marked with a white colored circle, which indicates that these particles possess regular cubic morphology and had smooth facies.

The influence of reaction time on the morphology of the products was also investigated and TEM images of iron oxides nanocubes obtained at $160^{\circ} \mathrm{C}$ using $3 \mathrm{~mL}$ triethylamine for $1,3,6$, and 12 hours were displayed in Figures 3(a), 3(b), 3(c), and 3(d), respectively. For a short reaction time of 1 hour, as shown in Figure 3(a), most of the synthesized particles were in irregular shape and the particle size varied a lot. Yet, by prolonging the reaction time, a tendency was deduced that the particles became more and more regular in size and morphology, and, gradually, these particles formed into cubic patterns, as shown in Figures 3(b), 3(c), and 3(d). Compared with these TEM date, prolonging the reaction time was helpful to the formation of iron oxides nanocubes.

3.3. FTIR Spectrum. Figure 4 represented the FTIR spectrum between 4000 to $400 \mathrm{~cm}^{-1}$ of $\alpha-\mathrm{Fe}_{2} \mathrm{O}_{3}$ nanocubes. The peaks 


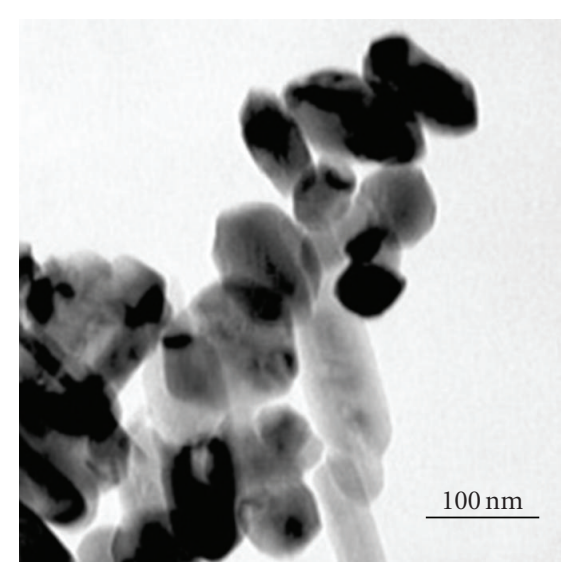

(a)

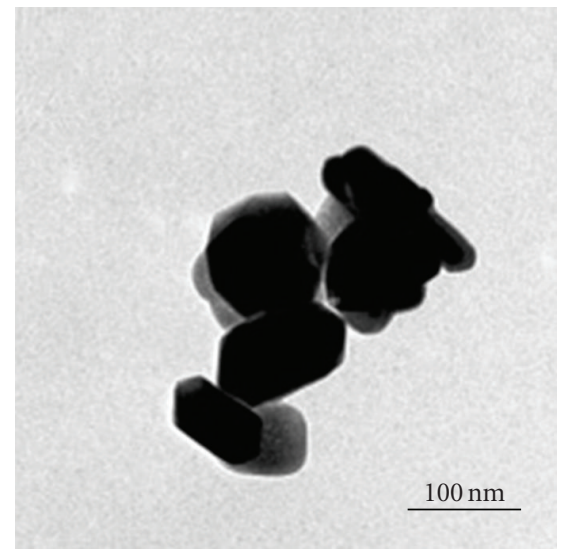

(c)

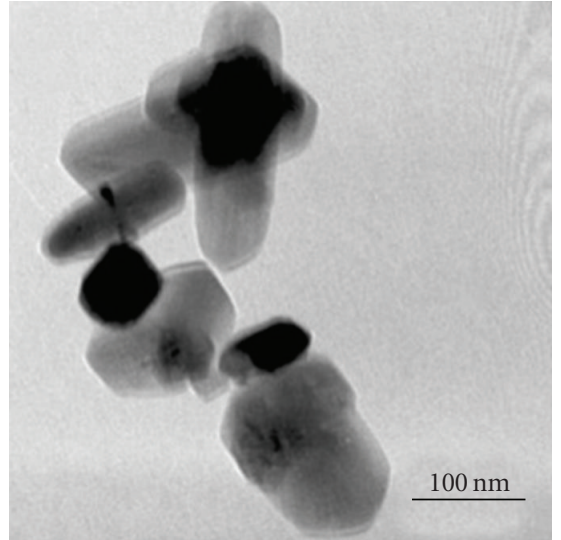

(b)

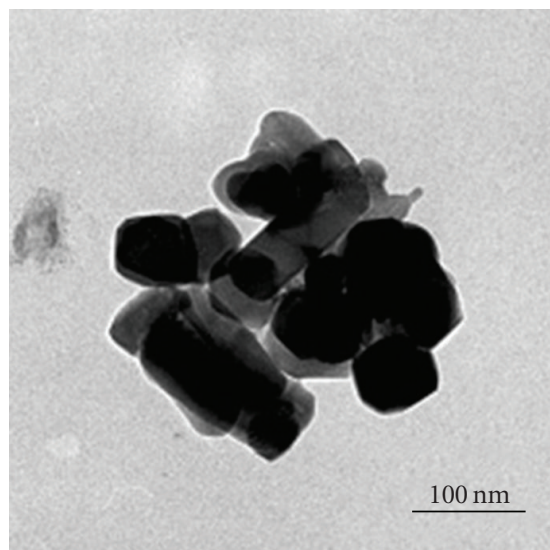

(d)

Figure 3: TEM images of $\mathrm{Fe}_{2} \mathrm{O}_{3}$ nanocubes were prepared at $160^{\circ} \mathrm{C}$ using $3 \mathrm{~mL}$ triethylamine for 1 hour (a), 3 hours (b), 6 hours (c) and 12 hours (d).

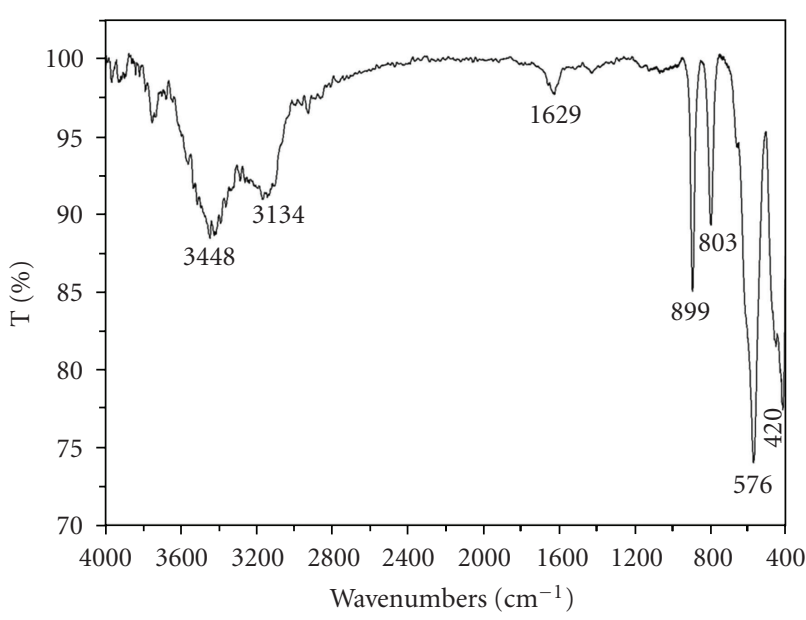

Figure 4: FT-IR image of $\mathrm{Fe}_{2} \mathrm{O}_{3}$ sample at $160^{\circ} \mathrm{C}$ using $3 \mathrm{~mL}$ triethylamine for 24 hours.

at 420 and $576 \mathrm{~cm}^{-1}$ attributed to the $\mathrm{Fe}-\mathrm{O}$ bond vibration of the $\mathrm{Fe}_{2} \mathrm{O}_{3}$. The spectrum showed the bands at 899 and $803 \mathrm{~cm}^{-1}$ corresponds to the out-of-plane $\mathrm{C}-\mathrm{H}$ vibration caused by the remnant of triethylamine on the surface of particles and the peaks at around $1629 \mathrm{~cm}^{-1}$ were tentatively assigned to the vibration of $\mathrm{C}-\mathrm{N}$ bond [16]. The peaks at $3134 \mathrm{~cm}^{-1}$ were assigned to the $v\left(\mathrm{~N}^{+}-\mathrm{H}\right)$ vibrations [17], and peaks at $3448 \mathrm{~cm}^{-1}$ were assigned to the $\mathrm{O}-\mathrm{H}$ stretching vibration of absorbed water.

\section{Discussion and Conclusion}

Iron oxide nanocubes were prepared by a hydrolysis reaction of $\mathrm{Fe}^{3+}$ in triethylamine at the temperature of $160^{\circ} \mathrm{C}$ and the triethylamine provides $\mathrm{OH}^{-}$to form the $\mathrm{Fe}(\mathrm{OH})_{3}$ deposition. After reacting in hydrothermal environment, the $\mathrm{Fe}(\mathrm{OH})_{3}$ translated into $\alpha-\mathrm{FeOOH}$ through heat decomposition at first, and then the $\alpha$-FeOOH translated into $\alpha-\mathrm{Fe}_{2} \mathrm{O}_{3}$ through heat decomposition (Figure 1). With the $\mathrm{Fe}_{2} \mathrm{O}_{3}$ crystal particles growing, the cubes were formed because triethylamine influenced the growth rate of some crystal faces. Furthermore, the iron oxide cubes' formation was influenced by reaction time. The formation mechanism and influenced factors of iron oxide cubes will be discussed thoroughly in our further investigation. 
In summary, iron oxide nanocubes were successfully synthesized via hydrothermal synthetic route under mild conditions. It is expected that the iron oxide of uniform nanocrystallines may be promoted to some important applications in fields, for example, sensors, magnetic media, and catalytic, and so forth. This synthetic approach provided a simple and economical route to synthesize Nanocrystals. We have also discovered that many of our synthesis techniques could be utilized in the preparation of other nanostructured metal oxides, which will be reported later.

\section{Acknowledgment}

This paper was supported by the National Natural Science Foundation of China (Project no. 50774094).

\section{References}

[1] P. Praserthdam, O. Mekasuwandumrong, J. Phungphadung, A. Kanyanucharat, and W. Tanakulrungsank, "New correlation for the effects of the crystallite size and calcination temperature on the single iron oxide nanocrystallites," Crystal Growth and Design, vol. 3, no. 2, pp. 215-219, 2003.

[2] D. S. Toledano and V. E. Henrich, "Kinetics of $\mathrm{SO}_{2}$ adsorption on photoexcited $\alpha-\mathrm{Fe}_{2} \mathrm{O}_{3}$," Journal of Physical Chemistry B, vol. 105, no. 18, pp. 3872-3877, 2001.

[3] A. W. Apblett, S. I. Kuriyavar, and B. P. Kiran, "Preparation of micron-sized spherical porous iron oxide particles," Journal of Materials Chemistry, vol. 13, no. 5, pp. 983-985, 2003.

[4] S. Sun, C. B. Murray, D. Weller, L. Folks, and A. Moser, "Monodisperse FePt nanoparticles and ferromagnetic FePt nanocrystal superlattices," Science, vol. 287, no. 5460, pp. 1989-1992, 2000.

[5] R. D. McMichael, R. D. Shull, L. J. Swartzendruber, L. H. Bennett, and R. E. Watson, "Magnetocaloric effect in superparamagnets," Journal of Magnetism and Magnetic Materials, vol. 111, no. 1-2, pp. 29-33, 1992.

[6] S. Chen, J. Feng, X. Guo, J. Hong, and W. Ding, "One-step wet chemistry for preparation of magnetite nanorods," Materials Letters, vol. 59, no. 8-9, pp. 985-988, 2005.

[7] M. Ocaña, M. P. Morales, and C. J. Serna, "Homogeneous precipitation of uniform $\alpha-\mathrm{Fe}_{2} \mathrm{O}_{3}$ particles from iron salts solutions in the presence of urea," Journal of Colloid and Interface Science, vol. 212, no. 2, pp. 317-323, 1999.

[8] Y. Ni, X. Ge, Z. Zhang, and Q. Ye, "Fabrication and characterization of the plate-shaped $\gamma-\mathrm{Fe}_{2} \mathrm{O}_{3}$ nanocrystals," Chemistry of Materials, vol. 14, no. 3, pp. 1048-1052, 2002.

[9] C. Gong, D. Chen, X. Jiao, and Q. Wang, "Continuous hollow $\alpha-\mathrm{Fe}_{2} \mathrm{O}_{3}$ and $\alpha$-Fe fibers prepared by the sol-gel method," Journal of Materials Chemistry, vol. 12, no. 6, pp. 1844-1847, 2002.

[10] X. Wen, S. Wang, Y. Ding, Z. L. Wang, and S. Yang, “Controlled growth of large-area, uniform, vertically aligned arrays of $\alpha$ $\mathrm{Fe}_{2} \mathrm{O}_{3}$ nanobelts and nanowires," Journal of Physical Chemistry B, vol. 109, no. 1, pp. 215-220, 2005.

[11] J. Cheon, N.-J. Kang, S.-M. Lee, J.-H. Lee, J.-H. Yoon, and S. J. Oh, "Shape evolution of single-crystalline iron oxide nanocrystals," Journal of the American Chemical Society, vol. 126, no. 7, pp. 1950-1951, 2004.

[12] Y. Hou, Z. Xu, and S. Sun, "Controlled synthesis and chemical conversions of FeO nanoparticles," Angewandte Chemie. International Edition, vol. 46, no. 33, pp. 6329-6332, 2007.
[13] T. Hyeon, S. S. Lee, J. Park, Y. Chung, and H. B. Na, "Synthesis of highly crystalline and monodisperse maghemite nanocrystallites without a size-selection process," Journal of the American Chemical Society, vol. 123, no. 51, pp. 1279812801, 2001.

[14] X. Liu, G. Qiu, Z. Wang, and X. Li, "Rationally synthetic strategy: from nickel hydroxide nanosheets to nickel oxide nanorolls," Nanotechnology, vol. 16, no. 8, pp. 1400-1405, 2005.

[15] C. J. Murphy, "Materials science: Nanocubes and nanoboxes," Science, vol. 298, no. 5601, pp. 2139-2141, 2002.

[16] G. Wojciechowski and B. Brzezinski, "Formation of hydrogenbonded chains through inter- and intra-molecular hydrogen bonds by 5,5'-dinitro-2,2'-biphenol with a strong base of guanidine-like character and triethylamine," Journal of Molecular Structure, vol. 607, no. 2-3, pp. 149-154, 2002.

[17] G. Wojciechowski and B. Brzezinski, "Formation of hydrogenbonded complexes of 3,3',5,5'-tetrabromo-2,2'-biphenol with MTBD and triethylamine," Journal of Molecular Structure, vol. 616, no. 1-3, pp. 67-71, 2002. 

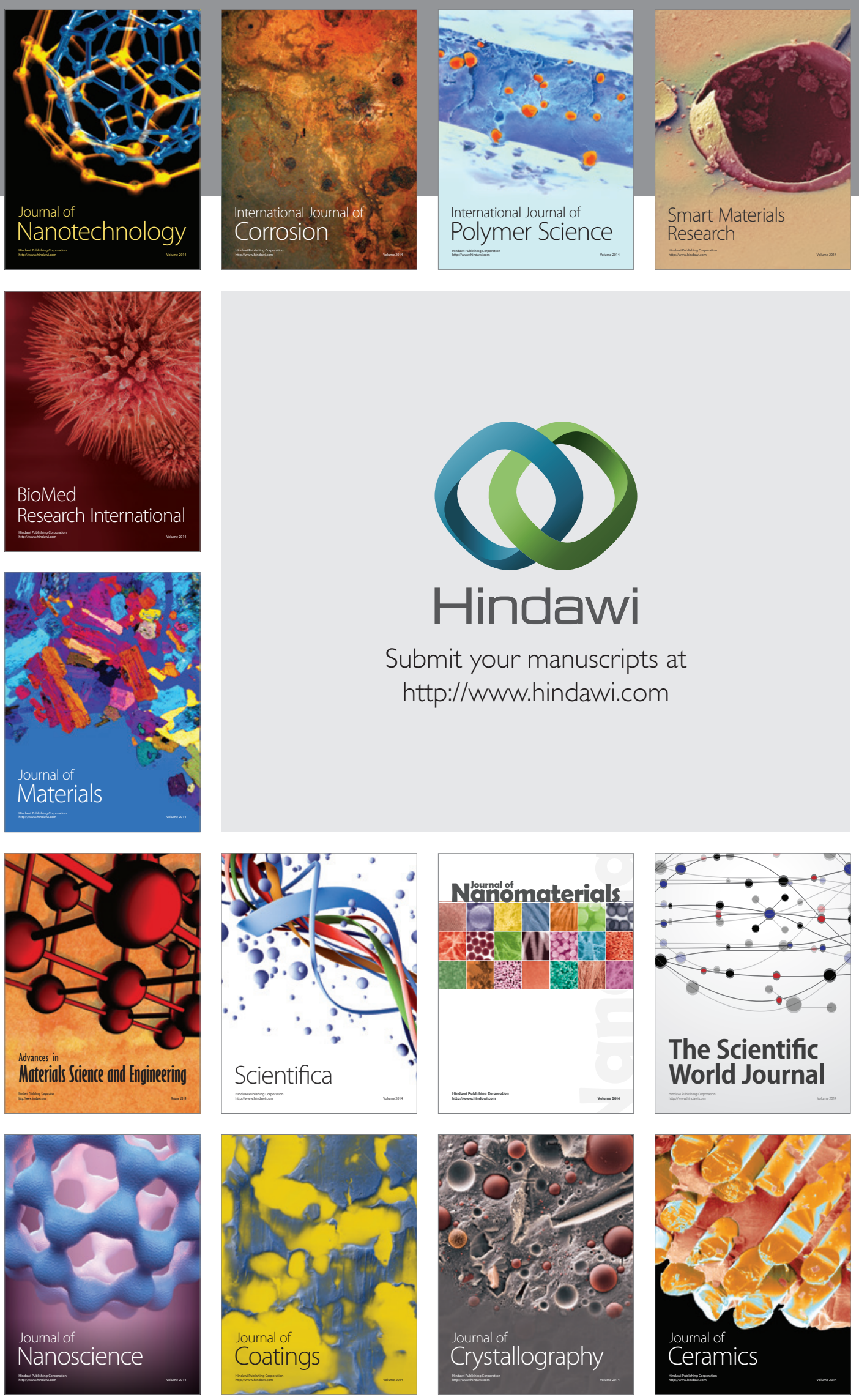

The Scientific World Journal

Submit your manuscripts at

http://www.hindawi.com

\section{World Journal}

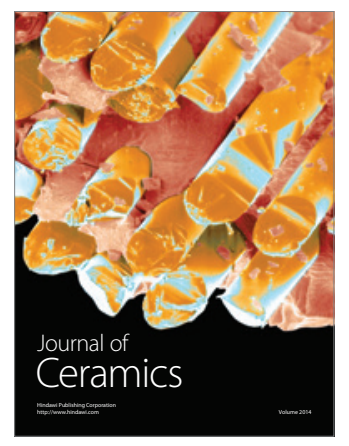

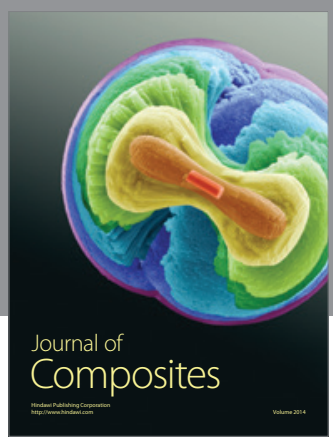
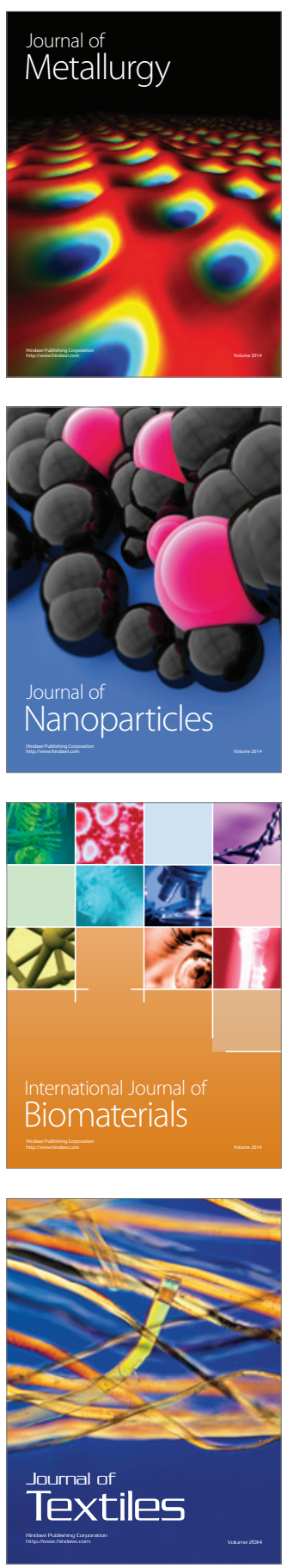